\title{
Innovative fuel cell buses with automated guidance by GPS for public transport application
}

\author{
M. Andriollo ${ }^{1}$, A. Caporali ${ }^{2}$, G. Martinelli ${ }^{1}$, A. Morini ${ }^{1}$, C. Morini ${ }^{3}$, \\ T. Pepi ${ }^{3} \&$ A. Tortella ${ }^{1}$ \\ ${ }^{1}$ Department of Electrical Engineering, Padova University, Italy \\ ${ }^{2}$ Department of Geosciences, Padova University, Italy \\ ${ }^{3}$ CISAS - Interdipartimental Centre for Space Activities, \\ Padova University, Italy
}

\begin{abstract}
This paper proposes the use of an innovative transport system based on electric buses, with on-board energy sources and automated guidance control by GPS. The on-board energy sources consist of fuel cells, supplied by ethanol fuel with or without on-board catalytic reformer. Electrical storage systems (batteries, supercapacitors) integrate the fuel cell for more efficient management of the energy exchange with the electric propulsion motors. The vehicle guidance and control are managed according to the signals provided by one or more GPS receivers, in conjunction with an inertial platform and numerical cartography. In this way the electrical steering, braking and propulsion functions can be governed electronically by means of drive-by-wire technology. This control leads to less driver engagement, full flexibility in the route definition and comfortable operation because of the optimised management of both the propulsion and the steering system. The features of the proposed transportation system are analysed and discussed in the paper.

Keywords: electric transport systems, fuel cell vehicles, automated guidance, drive-by-wire, in-wheel motors.
\end{abstract}

\section{Introduction}

The traffic expansion to wider and wider urban areas has increased the problems related to urban mobility, pollution and quality of life, mainly in mid-sized cities, 
which generally lack an extended and well-established public transportation network. Anyway, also in large cities an effective development of public transportation calls for an integration between traditional high capacity systems and more flexible solutions, with low infrastructural impact (mainly in downtown areas) and environmental-friendly characteristics. Such requirements can be satisfied by the on-board supplied electric buses, reducing noise and pollutant emissions, with enhanced control capability, leading to higher management efficiency of the operating conditions and of the energy flows.

Among this transport category, the fuel cell (FC) buses are probably the more suitable vehicles, because of their large operating range, differently from the battery vehicles, and because of their performances comparable to hybrid electric buses, with the advantage to meet the zero-emission requirement. The application of FC buses to public urban transport has already achieved good experimental results and growing commercial development is expected in the near future (Martinelli et al. [1], CUTE Project [2]). The paper proposes an innovative system, which integrates different advanced technologies relating the vehicle supply, propulsion and guidance.

The main features of the system are (Fig.1):

- FC supplied by ethanol fuel (DEFC), with or without on-board catalytic reformer;

- integration of the FC supply with electrical storage systems, such as batteries and supercapacitors (SC); more efficient management of the energy exchange with the electric propulsion motors is obtained by means of a DC link;

- propulsion by in-wheel synchronous permanent magnet motors (WM); this improves the total efficiency because of the gearbox removal and reduces weight and volume with respect to conventional propulsion and transmission equipments;

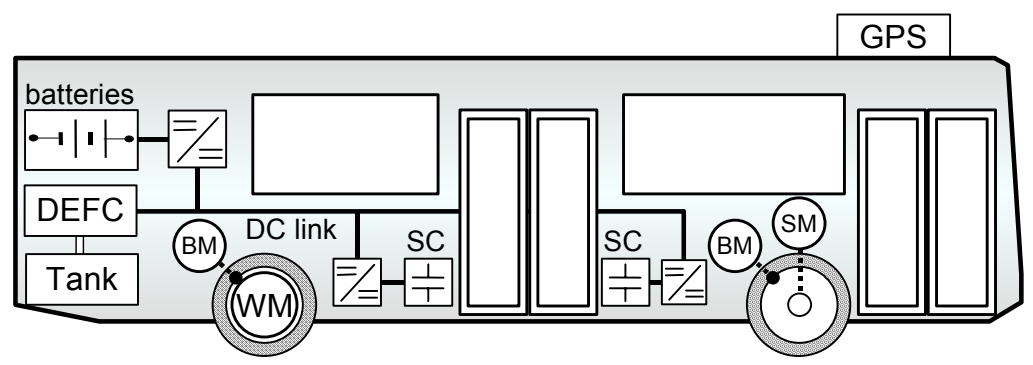

Figure 1: Main components of a FC bus. Power sources: direct ethanol fuel cell (DEFC) and supercapacitors (SC). Electric motors: steering $(\mathrm{SM})$, braking $(\mathrm{BM})$ and in-wheel (WM) motors. Guidance control: global positioning system (GPS).

- electrical steering (SM) and braking (BM) actuators, electronically governed according to a drive-by-wire technology;

- automated guidance control obtained by means of a global positioning system (GPS) receiver which, in conjunction with an inertial platform and numerical 
cartography, provides the position signal used to set the propulsion and steering commands.

A detailed description of the proposed powertrain architecture and of the main principles which define the control strategy is presented in the paper.

\section{Powertrain and control units}

The layout of the on-board power and control units is sketched in Fig.2. As regard the energy sources, the DEFC is rated to provide the average value of the total electric power demand, while the energy storage devices manage, through bi-directional converters, the power fluctuations related to different vehicle operations (Martinelli et al. [1]). The combination of batteries and supercapacitors seems to be the most favourable option, as the coexistence of high energy and power density sources provides reliable and efficient operation for different urban routes. In particular, batteries operate with slow variation of power demand because high rate discharges compromise their duration life; in addition, they can provide enough power to guarantee safe operation in case of FC failure. In the most general configurations, multiple SC banks are distributed in the powertrain near the main electric loads (the steering actuator, the braking motor and the wheel propulsion motor), all supplied by three-phase inverters: such solution allows to define the appropriate SC ratings according to the maximum load requirement and to minimise the DC link overload.

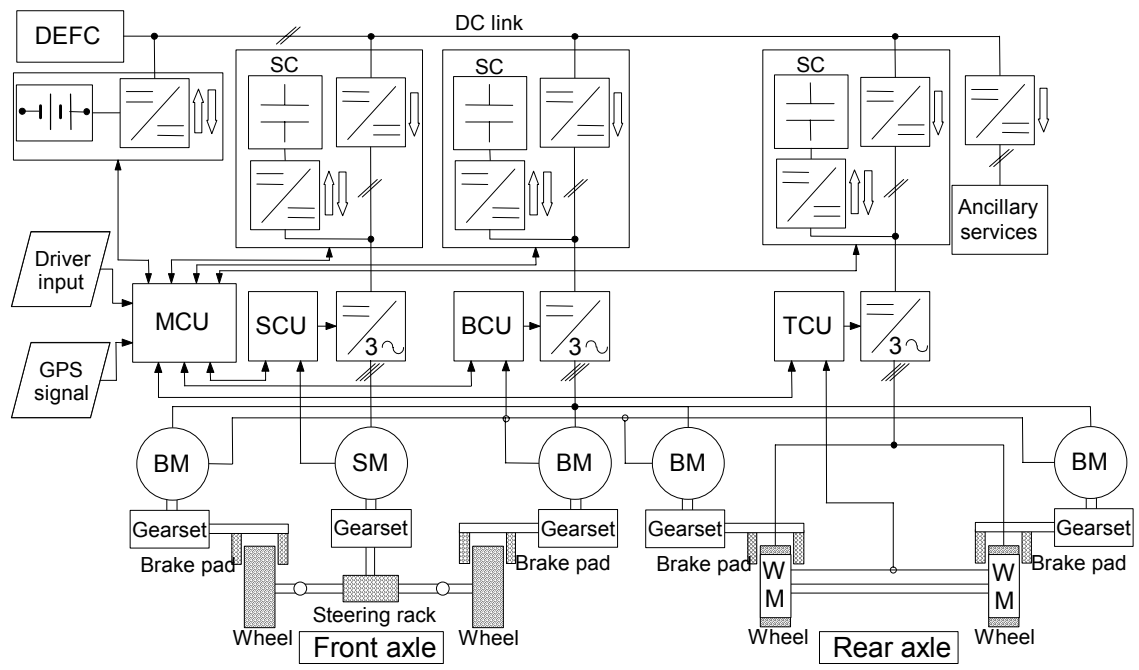

Figure 2: Powertrain and control components of the FC bus. Control units: main (MCU), steering (SCU), braking (BCU) and traction (TCU) units.

Thanks to their capability to deal with fast and repetitive charge and discharge processes, SC can handle short power peaks, which may occur during starting, acceleration/deceleration phases, emergency braking and variable steering 
conditions. Differently from other FC buses, the powertrain operation is governed by a main control unit (MCU), which receives the commands from the on-board GPS receiver or from the driver. The GPS receiver determines the vehicle position and orientation: after comparing the position with a predefined path stored in a map database, the MCU sets the appropriate commands to the steering devices and to the propulsion/braking sub-systems. This approach leads to less driver engagement, full flexibility in the route definition which can be adapted to urban mobility modifications, more efficient and comfortable operation for the optimised real-time control of the propulsion, braking and steering systems as well as of the automated coordination of a vehicle fleet. For safety reasons, the driver input should have anyway superior priority, providing the commands through the sensors mounted on the steering wheel, the accelerator or the brake pedal. In addition to the guidance and propulsion supervision, the MCU checks the SC and battery state of charge (SOC) and performs real-time diagnostics and protection, monitoring different parameters which can affect the control strategy.

\section{Direct ethanol fuel cell (DEFC)}

Most of FC buses under experimentation use solid polymer fuel cells, supplied by gaseous or liquid hydrogen $\left(\mathrm{H}_{2}\right.$-PEMFC). In spite of some favourable aspects related to the absence of on-board reforming and to the optimal cell operating efficiency, its inherent drawbacks are related to the hydrogen supplying and storage, the safe management of the on-board devices as well as of the depots. In order to overcome the difficulties, liquid fuels-fed (such as alcohols - methanol or ethanol) FCs have been considered, since such fuels can be oxidised inside the stack. Methanol presents high electrochemical activity and is consistent with most of the materials used in the pure hydrogen fuel cells (Thomas et al. [3]). Just for these favourable features, the direct methanol fuel cell (DMFC) has been already investigated with satisfactory results for some bus prototypes [4]. However, some problems must be considered, related to both the cell operation (for instance cross-over phenomena) and mainly to the high fuel toxicity.

The most promising methanol competitor is the ethanol, adopted in direct ethanol fuel cells (DEFCs, Bentley et al. [5]), with considerable benefits:

- with respect to methanol, it is not toxic, provides higher specific energy (8.1 versus $6.1 \mathrm{kWh} / \mathrm{kg}$ ) and is less dangerous in case of tank loss;

- it is naturally available by extraction from biomass (bio-ethanol) using fermentation processes of organic materials (sugar, starch, cellulose): these materials can be obtained from agricultural or agribusiness residuals (straw, sawdust, woody fibre, corn fibre, rice straw, potato wastes), ad-hoc growing (mainly sugar cane, sugar beet, sorghum, corn) or urban wastes;

- it comes from renewable resources, not changing the natural balance of carbon dioxide in the atmosphere, differently from the fossil fuels;

- a large scale supplying and distribution network is already existent (see Brazil and USA), similar to the fossil fuel one; in case, the same plants used for gasoline can be adapted with minor modifications; 

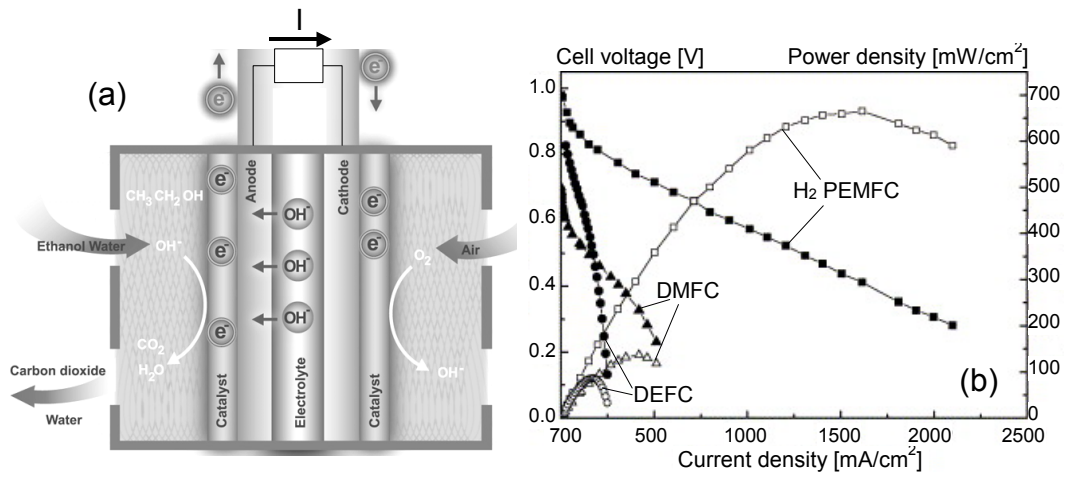

Figure 3: (a) DEFC operation [7]; (b) DEFC cell voltage (black markers) and power density (white markers) as current density functions (Song et al. [6]).

- conventional PEM-FC or SOFC (yet more suitable for stationary application because of the high operating temperature) can be used;

- it can be used to produce hydrogen by means of a POX reformer, with minimal CO residuals, higher system compactness than methanol or other fuels and higher commercial competitiveness.

It's worth to point out the higher global DEFC efficiency in comparison with the electrical generator coupled to internal combustion engine fed by ethanol: in fact, the latter solution requires an energy demanding concentration preprocessing to limit the presence of water in the combustion chamber. Of course the FC cost is still high, but significant reduction should be expected in the near future, due to the growing interest of FC application in industrial and transport fields.

The DEFC main parts and chemical reactions and its typical performances, described in detail in Song et al. [6] and [7], are shown in Fig.3. The main issues, aimed to obtain performances and costs comparable with the pure hydrogen or methanol-fed FCs, are related to the replace platinum catalysers with cheaper ones, yet not affected by the fuel cross-over, resistant to $\mathrm{CO}$ poisoning and stable also with high temperatures.

\section{Power steering system}

The electric powered steering systems introduce remarkable improvements with respect to the conventional mechanical and hydraulic components in terms of efficiency, reliability and safety (Rodriguez et al. [8], Mir et al. [9]).

The main components of the steering system are shown in Fig.4a: the power assist unit consists of an electrical motor (M) directly coupled to the steering column which applies a suitable force on the rack to steer the wheels.

The favourable features due to the electromechanical actuators instead of hydraulic ones (used in most of the up-to-date road vehicles) are:

- higher efficiency since M, unlike the hydraulic actuators, is supplied only during steering, reducing also the fuel consumption (about 3-5\%); 
- lower volume and weight (absence of the hydraulic pump and circuit);

- better driving control for wide speed ranges (particularly, the driver engagement at stall is greatly reduced by the electric powered steering);

- absence of liquid substances, difficult to recycle.
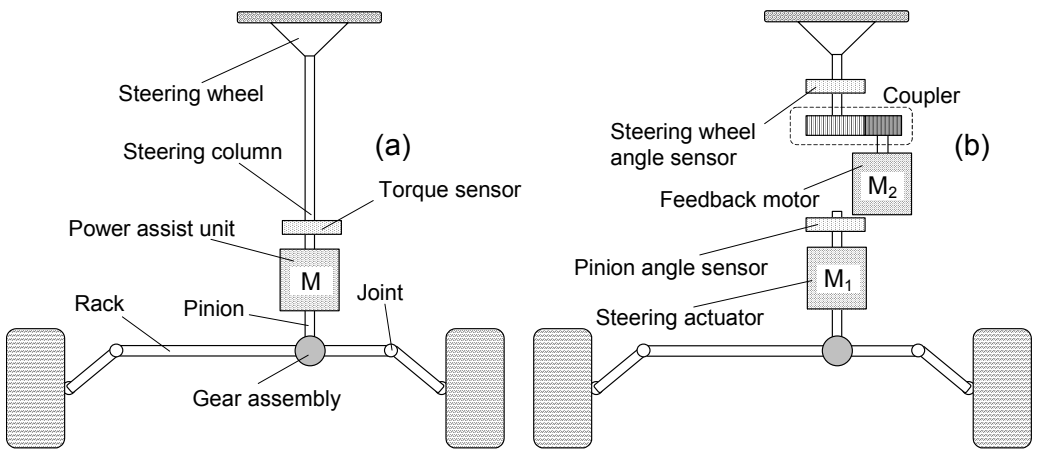

Figure 4: Electrical power steering; (a) electric motor (M) connected to the steering column; (b) steer-by-wire $\left(\mathrm{M}_{1}\right.$ : steer motor; $\mathrm{M}_{2}$ : feedback motor).

As for the electrical operation, $M$ is governed by a conventional electric drive: the control system gets the input torque command from the steering wheel sensor and elaborates the current and voltage references for the power converter, taking also into account the vehicle speed.

A further upgrade is represented on the steer-by-wire technology (SBW), whose components are shown in Fig.4b (Bertoluzzo et al. [10], Yih and Gerdes [11]). Two independent electric motors carry out the steering function (motor $\mathrm{M}_{1}$ ) and the wheel resistance feedback transmission to the driver (motor $\mathrm{M}_{2}$ ), allowing one to remove the connection between the steering wheel and actuators with several benefits regarding functionality, safety and costs, including:

- removal of the steering column, potentially dangerous in case of car crash;

- better driving comfort because the feedback system can filter possible vibrations induced by the road surface; in addition, the steering wheel positioning can be more ergonomic and flexible, because of the absence of mechanical connection constraints with the steering system;

- the possibility to implement independent wheel steering which easies the parking and manoeuvring operations;

- the increase of vehicle stability by controlling also the lateral dynamics with response time lower than the one related to driver action.

Reliability and safety considerations call for the fulfilment of several constraints (Yao et al. [12]). First of all, an almost real time control of the vehicle direction (wheel synchronisation) is required, set by the GPS signal or by the steering wheel. In addition, the feedback signal to the steering wheel must be elaborated, reproducing the ground reaction on the wheels. Further requirements are the automatic wheel re-alignment with unhanded steering wheel and the variable steering ratio, with better performances and vehicle dynamics with 
respect to the conventional fixed steering ratio. Finally, the reliability concern requires the implementation of suitable architectures, choosing among hydraulic or mechanical backups, the redundancy of the main system components, the use of fault-tolerant configurations of converters and electric motors (for instance multi-phase motors) in order to have acceptable performances also during fault conditions (i.e., low short circuit current and torque as for the electric motors).

The main SBW components are the control unit and the electric drive system. The control unit elaborates in real-time the input signals coming from the steering wheel and from the wheels (angle and torque), from the vehicle (yaw angle, lateral acceleration, speed) and from the electric motors (position, current and temperature), filtering possible disturbances, to generate the position and torque references. Such signals drive the commutation of the converter electronic switches according to a suitable control strategy (for instance PWM), depending on the kind of electric motor. The DC servomotor drives are relatively cheap and easy to control, but need frequent maintenance because of the brush/commutator and then cannot fulfil the reliability constraints. The state-of-art solutions rely on drives employing inverter-fed induction motors, DC brushless or permanent magnet (PM) synchronous motors (Benedetti et al. [13], Liu et al. [14]).

Besides the above mentioned requirements, the steering motors are required to have very low torque ripple to limit the mechanical vibrations and noise, high efficiency, high specific power and power density to reduce the overall dimensions. Such specifications often lead to conflicting design requirements, calling for sophisticated tools for the electromagnetic analysis, such numerical codes based on the finite element method (FEM).

The internal PM (IPM) motor provides a high power density thanks to the remarkable reluctance torque, absent in the surface PM (SPM) motors, but with an inherent higher cogging torque: particular arrangements (slot skewing, skewing of multiple rotor modules) are therefore required, complicating the motor assembly and increasing its cost. Alternative proposed configurations are:

- switched reluctance motors (SRM) fed by power converters with limited number of unipolar switches (Dilger et al. [15]);

(a)

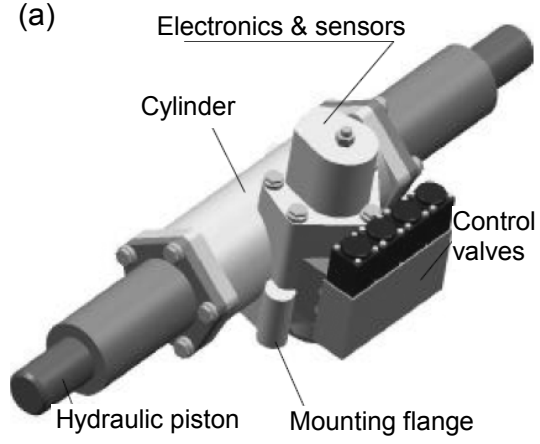

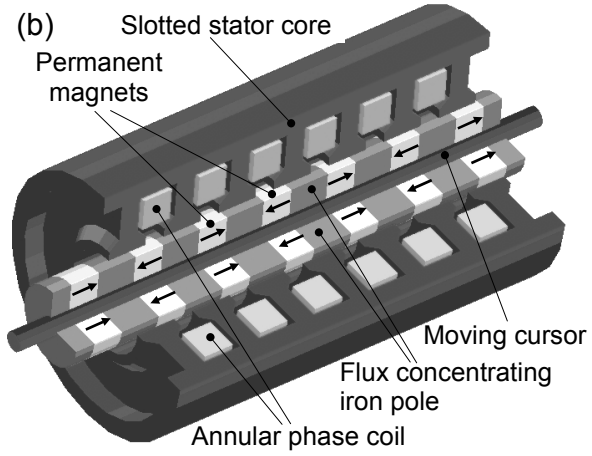

Figure 5: Comparison of steering actuators; (a) hydraulic piston controlled by electro-valves; (b) linear electromagnetic actuator with tubular configuration. 
- six-phase squirrel cage induction motors fed by converters with limited switch number (Aroquiadassou et al. [16]).

Other studies are in progress, focused on the use of linear motors with the slider directly connected to the steering rack. As shown in Fig.5, the hydraulic piston (Fig.5a) is replaced by an electromagnetic cursor driven by a short stator PM tubular motor (Fig.5b) (Schofield et al. [17]). In order to obtain adequate force densities, an iron-core configuration is proposed with sintered $\mathrm{NdFeB}$ magnets, inserted in ferromagnetic poles concentrating the magnetic flux (internal magnet topology). The lumped coils are positioned in semi-closed stator slots to increase the mean air-gap flux density and to reduce the teeth cogging force.

\section{$5 \quad$ Electromechanical braking}

Likewise steering, the wheel braking can be realized via electromechanical systems (EMB), driven by the signals provided by a suitable electronic unit, replacing the traditional hydraulic linkage between the brake pedal and the wheels. The commonly proposed configuration (Fig.6a) consists of a rotary motor coupled to a planetary-gear and ball-screw assembly converting the motor rotation and torque into linear force (Ueki et al. [18]): two brake pads of a calliper structure apply a suitable clamp pressure on the disc fixed to the wheel, according to the torque command received from the electric motor. An alternative braking system is realized by the so-called wedge electromagnetic brake, whose tested prototype is shown in Fig.6b (Ho et al. [19]).

With respect to the conventional electro-hydraulic actuators, the EMB system leads to several benefits (Balazovic [20]):

- shorter stopping distances, optimised stability and comfort, because of the better accuracy also in case of small command signals;

- superior capability to implement all the required braking and stability functions, such as ABS, EBD, TCS, ESP, BA, ACC, etc;

- low noise and vibrations transmitted to the pedal, absence of hydraulic fluids;

- room and volume saving because of the compact and simple assembly;

- easier networking with future traffic management systems;

- possibility to integrate additional functions, such as electric parking brake.

As regards the electric motor, SRM and PM brushless drive systems seem to be the best candidates, because they provide high dynamics, possibility of 4-quadrant operation and good packaging options (Omekanda et al. [21], Klode et al. [22]). The SRM favourable features are the temperature independent torque, high mechanical bandwidth due to the small inertia, inherent fault tolerance thanks to the phase independent supply, high speed capability and adaptability to sensorless or semi-sensorless drives, enabling some cost saving. Nevertheless, some drawbacks have to be considered:

- the highly non-linear behaviour of the electromechanical and electromagnetic characteristics, requiring high control accuracy of the switches;

- the small air-gap and the complicated converter structure, increasing the manufacturing and the electric drive costs; 

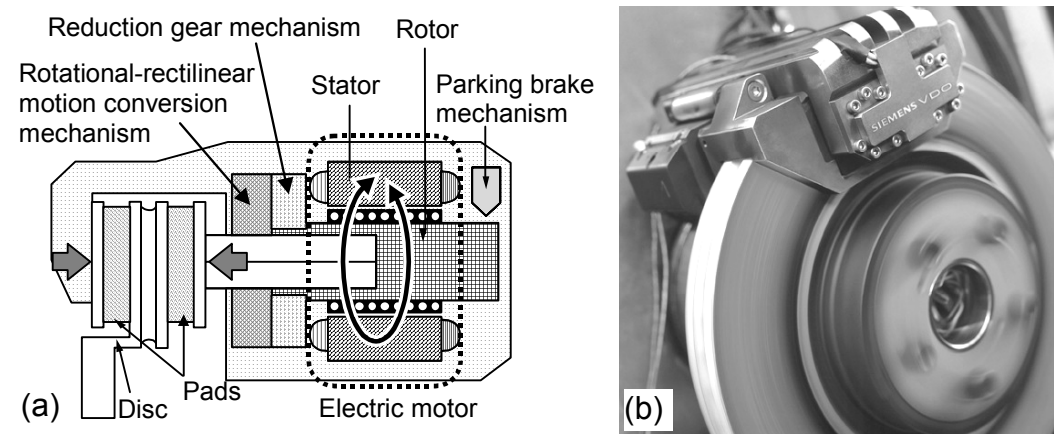

Figure 6: EMB (a) scheme (Ueki et al. [18]) and (b) prototype (Ho et al. [19]).

- the acoustical noise due to the torque production mechanism.

Some tests have been made by simulating different brake conditions (brake application, brake release, set of sudden direction reversals) and by monitoring different performance indexes, such as the response time and the instantaneous input current after a brake application, the active and the self-release time for a sudden brake loss, the force overshoot and undershoot during a brake release and reapply. The results obtained for a typical range of torque/speed specifications (torque $1 \mathrm{Nm}$ or less, base speed $1500 \mathrm{rpm}$ or less) have shown very good dynamic performances for both SRM and PM brushless solutions, though the latter seem to be more convenient in terms of compactness and control flexibility (Omekanda et al. [21]). Brake actuators based on linear PM motors have been also proposed (Zhu et al. [23]): by choosing a particular flux focusing configuration, good force capability and controllability have been obtained, though the fulfilment of cost and volume targets requires further investigations.

\section{In-wheel motors}

The use of synchronous PM motors inside the wheel (in-wheel motors) is convenient because of the increase of the available payload space, the gearless configuration (higher efficiency, reduced maintenance), the fewer moving parts as the axle is stationary, the absence of the field winding losses and the torquespeed characteristic suitable for the urban operation. The rotor is directly coupled to the rim which is suspended on bearings mounted on the fixed shaft, where the stator iron core and the armature are installed. Several magnetic configurations have been analysed, differing according to the flux distribution (Martinelli et al. [1], Andriollo et al. [24], Rahman et al. [25]), but the best performances are obtained with the radial flux (RFPM) and axial flux (AFPM) configurations with surface PMs. As an example, a 24 poles RFPM configuration (Fig.7) has been studied at the University of Padova (Andriollo et al. [26]) and the values of the quantities related the motor performances at rated condition are given in Table 1. The motor shows good performances as regard both the specific torque and the 
electromagnetic efficiency (ratio between the electromagnetic losses and the converted power). The RFPM is also favourable for manufacturing aspects, the easier assembly of the stator lamination stack and rotor installation in the wheels.

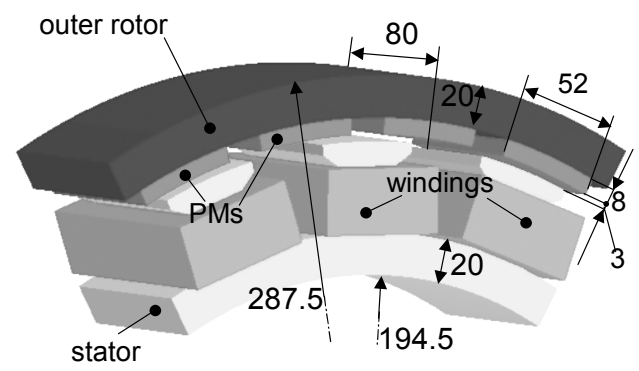

Table 1: Performance of the RFPM motor of Fig.7.

\begin{tabular}{|l|ll|}
\hline Rated power & $59.2 \mathrm{~kW}$ \\
\hline Specific torque & $14.1 \mathrm{Nm} / \mathrm{kg}$ \\
\hline Rated frequency & $102.0 \mathrm{~Hz}$ \\
\hline Current density & $8.0 \mathrm{~A} / \mathrm{mm}^{2}$ \\
\hline Copper losses & $1632 \mathrm{~W}$ \\
\hline $\begin{array}{l}\text { Electromagnetic } \\
\text { efficiency }\end{array}$ & $95.5 \%$ \\
\hline
\end{tabular}

Figure 7: 4-poles section of a RFPM inwheel motor (sizes in $\mathrm{mm}$ ).

\section{GPS components and control strategy}

Reliable and accurate vehicle position information are the major targets of various vehicle guidance and safety-related applications as it can be the one addressed in such work. The principal factors which should be taken into account in designing a public transport positioning system, which has to be developed in a real world dynamic environment, are:

- security: a position error in a single vehicle can jeopardize the safety of the inboard people and of all surroundings vehicles;

- immediate response: a safety-critical event often lasts for a relatively short time span with respect to the driver and vehicle dynamics;

- accuracy: the positioning system should, at the very least, be able to distinguish between lanes;

- latency and bandwidth: the timing and update rate for the sensors and signal processing should be fast enough compared to the vehicle dynamics;

- reliability and availability: the positioning system should be able to provide accurate positioning information under all normal conditions and locations;

- costs: economical implementation is of a significant deployment concern.

Thus, for most vehicle guidance or driver alert/assistance applications, the objective which determines the design features is not only, centimeter-level accuracy, but rather fast convergence and fast recovery system able to provide sufficient and reliable positioning information under all operational conditions. One option, chosen for this application, employs the satellite-based global positioning system (GPS) or differential GPS (DGPS) to determine the vehicle positions. This choice presents several advantages, the most significant of them are, for instance, the low cost of the "roadway" infrastructure, the possibility of integrate satellites data with additional information such as path preview and roadway data provided by vectorial cartography, a high precision over time and, most of all, the availability of GPS signals in all weather conditions. 
On the other hand, a system based only onto GPS (or DGPS) system presents some drawbacks, such as low update rate (generally $1 \mathrm{~Hz}$, while the fundamental vehicle dynamics, generally below $2-3 \mathrm{~Hz}$, requires a $10 \mathrm{~Hz}$ update with $50 \mathrm{~ms}$ delays at least), measurement latency, vulnerability to jamming and interference and most of all, lack of signal due to some obstacles (trees, buildings, tunnels, dense foliage etc.) and multipath effect.

To improve the positioning performance with the GPS/DGPS, a solution is to integrate it with an Inertial Navigation System (INS), generally composed of accelerometers, gyroscopes, and, in case, magnetometers. INS sensors are commonly integrated with GPS measurements in a Kalman filter (KF) or an Extended Kalman Filter (EKF) structure. In literature different KF-based GPS/INS integration methods are proposed and they can be classified into two categories:

1. GPS-aiding INS where the states in the extended Kalman filter are the INS sensors and the inputs to EKF are measurement residuals between INS and GPS (Wei et al. [27], Farrel et al. [28], Tan et al. [29], Yih et al. [30], Roth et al. [31]).

2. INS-aiding GPS where the EKF states are the INS integration states and the EKF inputs are GPS measurements (Huang et al. [32] and Tan et al. [33], Ryu et al. [34], [35] and [36], Redmill et al. [37]).

\section{DGPS-aided INS approach}

Farrel in his work [28] proposes a steering control process based on a carrier phase (CP) DGPS-aided INS algorithm (Fig. 8) providing the full vehicle state and trajectory information (for instance curvature) and a magnetic sensor to obtain highly reliable and accurate measurements (standard deviation $\approx 1 \mathrm{~cm}$ ).

The INS is the primary navigation system which calculates the navigation state $x$ plus a predominantly low-frequency error $\delta x$, at the high rate at which it is used by the control system processing the IMU (Inertial Measurement Unit) outputs. The output is filtered $\left(H_{1}\right.$ and $\left.H_{2}\right)$ and processed to provide an estimate of the DGPS carrier phase and Doppler measurements $(R$ and $D)$. INS state is corrected using the error estimates after each CP DGPS update. The DGPS aiding information is used when it is available and satisfies conditions designed to verify proper sensor operation. When such aiding sensor information is not available or judged inaccurate, the INS continued its normal (unaided) operation (transformation and integration of IMU outputs). The error state estimator is implemented by the EKF. $d$ and $\varepsilon_{r}$ represent respectively the distance from the known vehicle location and they trajectory relative to the yaw angle.

An alternative approach uses corrections to the code, rather than on the phase. The advantage is the immunity from cycle slips and initialization processes, which cannot be afforded in an operational context such as urban transportation. The drawback is a worse accuracy than in the CP DGPS, but this is irrelevant for accuracies better than $1 \mathrm{~m}$. Additional benefit comes from numerical cartography and lane modelling by polylines, and from the fact that RTCM code corrections 
can be generated in a network solution and tuned to the user position, according to schemes such as VRS (Virtual Reference Station) or MAC (Master Auxiliary Concept based on a grid of reference stations with the same ambiguity order).

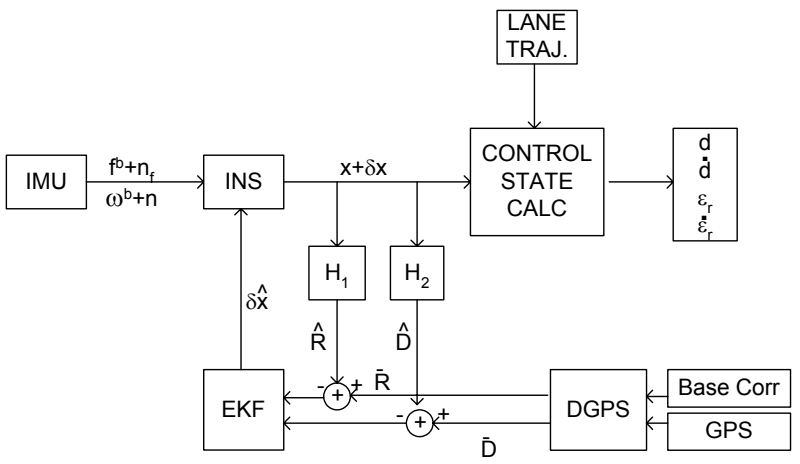

Figure 8: Control state block diagram for the DGPS-aided INS architecture.

\section{INS-aided GPS approach}

An INS-aided GPS position estimator is proposed in Fig. 9. A noise preprocessor can be added to filter DGPS measurements before feeding them to the EKF (Huang and Tan [32]). The inputs to the EKF are the longitudinal velocity $\left(u_{x}\right)$ from the wheel speed sensor, the yaw rate $\left(\omega_{z}\right)$ from the yaw gyro and the random Gaussian white noise $\left(n_{\omega b}\right)$, while the adjusted DGPS measurements are given by the vehicle position and heading angle $\left(x_{m}, y_{m}\right.$ and $\varphi_{m}$ respectively).

The DGPS error pre-processor is necessary to deal with the different error sources which affect GPS measurements. In DGPS applications essentially four types of noise can be observed: 1) noise with clear statistical properties such as ionospheric and tropospheric delays and some receiver electronic noise; 2) nonstationary noise due to satellite geometry distribution changes; 3) multipath or sudden spikes; 4) blockage or lack of DGPS output.

As the satellites gradually change their relative locations in the sky, the statistical properties in the first type of noise changes gradually and the mean of DGPS data drifts slowly (second type of noise).

In typical urban driving scenario where the type span of interest is relatively short (more or less $30 \mathrm{~s}$ ) and the changes in satellite distributions rather dynamic, noise appears to be more similar to a bias that changes when there is a variation in the visible satellite distribution.

Fig. 9 shows also a heading angle adjustment module. A typical GPS unit provides the vehicle heading angle (over ground) based on Doppler effects, the variance of this output depends on the satellite conditions as well as vehicle speed. When the speed drops below a certain threshold, the variance usually increases significantly. With a single antenna GPS it is common to discount the DGPS angle measurements at low speeds and estimate the heading angle in a open loop model. Urban driving manoeuvres, however, may include large 
steering changes which often exceed the model's ability to predict. Since lowspeed driving is a crucial element in public transport systems, which are characterized by a continuous "stop and go" situation, it is desirable to allow the heading angle rapid adjustments.

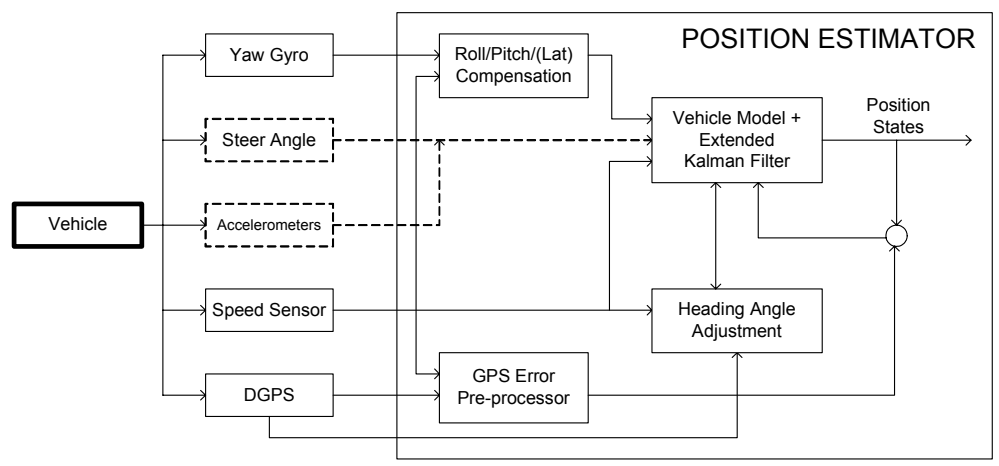

Figure 9: Block diagram of the INS-aided GPS position estimator.

One option could be to introduce an external modification to EKF in order to admit heading angle adjustment, during either initialization or any instances when reinitialization is required. An algorithm, based on DGPS quality and speed, has to be implemented to check the consistency of DGPS heading angle measurements and modify the EKF heading angle estimates accordingly (for more details see Huang and Tan [32]). Alternatively, a very effective way of monitoring the heading angle of the vehicle even at low or zero speed uses a pair of GPS antennas working in interferometric mode. Basically, it sufficient to add one more antennas to the one used in positioning, at a known distance (e.g. $0.5 \mathrm{~m}$ typical), provided both receivers track the L1 carrier phase (Caporali [38], Caporali and Dalla Torre [39]). A real time software compares the phases at the receivers and inverts the differential phases to obtain heading (yaw) and elevation angle (pitch) of the baseline joining the two antennas. Accuracies to fractions of a degree are typical, and the sampling frequency can be as high as 10 Hz. The azimuth angle recovered by this technique can be used to calibrate the reading of a low cost gyroscope. In turn the gyro data can be used to interpolate between the GPS measurements. This holds true also in case of limited satellite visibility, although it should be kept in mind that the gyro degrades the quality of its data very rapidly, and eventually the GPS azimuth will be the most accurate (Fig. 10).

\section{Error sources}

The accuracy of GPS position measurements depends on the quality of the observation measurements and satellite ephemeris data.

For urban public transport applications which mean low speed, multipath effect, and a "stop and go" constant situation, it appears easier to deal with pseudorange observations, eventually phase smoothed. The major GPS error 
sources are essentially atmospheric errors, including variable propagation rates and refractions, multipath errors and satellite clock and ephemeris data errors. A rough idea of the average magnitude orders of the errors is given by Table 2 .

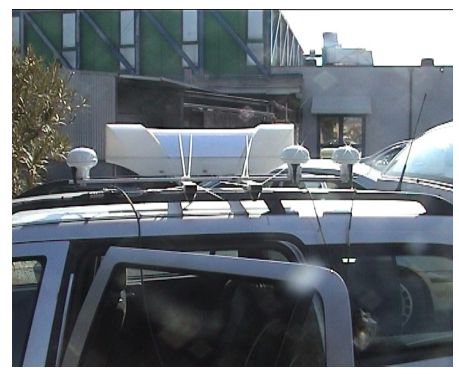

Figure 10: Attitude sensor prototype under development at the University of Padova being tested against a commercial sensor SIMRAD with GPS and gyro.

Table 2: $\quad$ Typical error budget.

\begin{tabular}{|c|c|c|}
\hline ERROR SOURCES & GPS & DGPS \\
\hline Satellite clock & $1.5 \mathrm{~m}$ & $0 \mathrm{~m}$ \\
\hline Orbit Error & $2.5 \mathrm{~m}$ & $0 \mathrm{~m}$ \\
\hline Ionosphere & $5.0 \mathrm{~m}$ & $0.4 \mathrm{~m}$ \\
\hline Troposphere & $0.5 \mathrm{~m}$ & $0.2 \mathrm{~m}$ \\
\hline Receiver Noise & $0.3 \mathrm{~m}$ & $0.3 \mathrm{~m}$ \\
\hline Multipath & $0.6 \mathrm{~m}$ & $0.6 \mathrm{~m}$ \\
\hline RSS & $\mathbf{5 . 8 5} \mathbf{~ m}$ & $\mathbf{0 . 8 1} \mathbf{~ m}$ \\
\hline
\end{tabular}

\section{Proposed final solution}

Considering the peculiarity of urban public transport applications and its specific requirements (fast convergence, error recovery under noisy situations) an approach able to combine the advantages of both the INS-aided GPS and GPSaided INS methodology appears to be the more adequate to describe more accurately all the involved phenomena.

The solution proposed by University of Padova integrates the data provided by a network of reference stations providing differential corrections (RTCM) in real time for each point of the network area (VRS or MAC) with the outputs of an attitude sensor based onto an interferometric approach (double differences of to phase observations). The attitude sensor combines an inertial platform and GPS antennas in order to get, in real time, heading and pitch angles which, combined the real time differential corrections, provide a complete, accurate, precise, reliable solution with high degree of error recovery also in case of limited satellite visibility. The interferometric attitude sensor is now under development and has been already suited for different applications (telecommunication antennas tracking, detection of ground deformation). A local 
augmentation system able to provide additional information in real time to the users in proximity to the reference stations in terms of signal integrity, accuracy, error forecasting and validity and real time corrections could be used to further improve the final guidance system performances (Di Corato et al. [40]). University of Padova is actually studying and implementing, under the GALILEA project co-funded by GSA (GNSS Supervisor Authority), a local augmentation system optimized to provide the best performances using both GPS and GALILEO signals. Furthermore, the University of Padova, is setting up a reliable and permanent network of reference stations able to provided in real time RTCM corrections with a VRS solution offering an almost complete covering of the regional area. Combining these data with the ones provided by the nearest region it is possible to achieve wider area coverage, characterized by high degree of accuracy, reliability and redundancy, an essential feature for applications involving public transportation.

\section{Conclusions}

The adoption of innovative on-board power sources, of fully electric powered apparatus for the propulsion, steering and braking and of GPS-based automated guidance system may represent distinctive features in prospective environmental friendly high performance vehicles for urban public transportation, offering safe, reliable and flexible operation at the same time.

The paper describes the main characteristics of the subsystems and the opportunities offered by their integration into a fully electric powered system, outlining the still existing main difficulties and drawbacks. An up-to-date experimental application combining INS and GPS, based on an attitude sensor prototype under development at the University of Padova, is described in detail.

\section{References}

[1] Martinelli, G., Morini, A., Tortella, A., Innovative Technologies for Public Electric Transport Systems, Urban Transport XI - Urban Transport and the Environment in the 21st Century, Vol.1, pp.569-579, 2005.

[2] CUTE Project, Detailed Summary of Achievements, www.fuel-cell-busclub.com, May 2006.

[3] Thomas, S.C., Ren, X., Gottesfeld, S., Zelenay, P., Direct methanol fuel cells: progress in cell performance and cathode research, Electrochimica Acta, Vol.47, pp.3741-3748, 2002.

[4] Georgetown University, Advanced Vehicle Development - The Fuel Cell Bus, Program Summary, http://fuelcellbus.georgetown.edu, April 2006.

[5] Bentley, J., Derby, R., Ethanol \& Fuel Cells: Converging Paths of Opportunity, Renewable Fuels Association White Paper, www.ethanolrfa.org, 2002.

[6] Song, S., Tsiakaras, P., Recent Progress in Direct Ethanol Proton Exchange Membrane Fuel Cells (DE-PEMFCs), Applied Catalysis - B: Environmental, Vol.63, pp.187-193, 2006. 
[7] www.acta-nanotech.com, February 2007.

[8] Rodriguez, F., Uy, E., Emadi, A., Brushless DC Motor Drive for SteerBy-Wire and Electric Power Steering Applications, Conf. on Electrical Insulation and Electrical Manufacturing \& Coil Winding Technology, Indianapolis, USA, 23-25 Sept. 2003, pp.535-541.

[9] Mir, S., Islam, M.S., Sebastian, T., Role of Electronics and Controls in Steering Systems, 29th Annual Conf. of the IEEE Ind. Electronics Society (IECON03), Roanoke, USA, 2-6 Nov. 2003, Vol.3, pp.2859-2864.

[10] Bertoluzzo, M., Bolognesi, P., Bruno, O., Buja, G., Landi, A., Zuccollo, A., Drive-by-Wire Systems for Ground Vehicles, IEEE Intl. Symp. on Ind. Electronics (ISIE 2004), Ajaccio, France, 4-7 May 2004, Vol.1, pp.711716.

[11] Yih, P., Gerdes, J.C., Modification of Vehicle Handling Characteristics via Steer-by-Wire, IEEE Trans. On Control Systems Technology, Vol.13, N.6, Nov. 2005, pp.965-976.

[12] Yao, Y., Vehicle Steer-by-Wire System Control, SAE World Congress, Detroit, USA, 3-6 Apr. 2006, SAE Tech. Paper 2006-01-1175.

[13] Benedetti, A., Bianchi, N., Bolognani, S., Dai Pré, M., Molari, P.G., Morelli, P., Tomasini, M., Tubiana, L., Zigliotto, M., PM Motor Drives for Steer-by-Wire Applications, 40 ${ }^{\text {th }}$ Ind. App. Conf. - IAS Annual Meeting, Hong Kong, 2-6 Oct. 2005, Vol.4, pp.2857-2864.

[14] Liu, G., Kurnia, A., De Larminat, R., Desmond, P., O’Gorman, T., A Low Torque Ripple PMSM Drive for EPS Applications, $19^{\text {th }}$ Annual IEEE Applied Power Electronics Conf. and Exposition (APEC04), Anaheim, USA, 22-26 Feb. 2004, pp.1130-1136.

[15] Dilger, E., Karrelmeyer, R., Strambe, B., Fault Tolerant Mechatronics, $10^{\text {th }}$ IEEE Intl. On-Line Testing Symposium (IOLTS'04), Funchal, Portugal, 12-14 July 2004, pp.214-218.

[16] Aroquiadassou, G., Henao, H., Lanfranchi, V., Betin, F., Nahidmobarakeh, B., Capolino, G.A., Biedinger, J.M., Friedrich, G., Design comparison of two rotating electrical machines for $42 \mathrm{~V}$ electric power steering, IEEE Intl. Conf. on Electric Machines and Drives (IEMDC05), S. Antonio, USA, 15-18 May 2005, pp.431-436.

[17] Schofield, N., Canova, A., Ottella, M., A Tubular Linear Actuator for Steer-By-Wire Applications, $4^{\text {th }}$ Intl. Symp. on Linear Drives for Ind. Applications (LDIA2003), 8-10 Sept. 2003, Birmingham, UK, pp.560-563.

[18] Ueki, N., Kubo, J., Takayama, T., Kanari, I., Uchiyama, M., Vehicle Dynamics Electric Control Systems for Safe Driving, Hitachi Review, Vol.53, No.4, pp.222-226, 2004.

[19] Ho, L. M., Roberts, R., Hartmann, H., Gombert, B., The Electronic Wedge Brake - EWB, SAE Tech. Paper 2006-01-3196, 2005.

[20] Balazovic, P., 56F8300 Hybrid Controller Used in Control of ElectroMechanical Brake, www.freescale.com, Nov. 2004.

[21] Omekanda, A.M., Lequesne, B., Klode, H., Gopalakrishnan, S., Husain, I., Switched reluctance and permanent magnet brushless motors in highly 
dynamic situations: A comparison in the context of electric brakes, $41^{\text {st }}$ IEEE Ind. Applications Conf., Tampa, USA, 8-12 Oct. 2006.

[22] Klode, H., Omekanda, A.M., Lequesne, B., Gopalakrishnan, S., Khalil, A., Underwood, S., Husain, I., The Potential of Switched Reluctance Motor Technology for Electro-Mechanical Brake Applications, SAE World Congress, Detroit, USA, 3-6 Apr. 2006, SAE Tech. Paper 2006-010296.

[23] Zhu, Z.Q., Jewiell, G.W.N., Howe, D., Design considerations for permanent magnet polarized electromagnetically actuated brakes, IEEE Trans. on Magnetics, Vol.31, No.6, pp.3743-3745, Nov. 1995.

[24] Andriollo, M., Bettanini, G., Martinelli, G., Morini, A., Stellin, S., Tortella, A., Electromagnetic Design of In-wheel Permanent Magnet Motors, WSEAS Trans. on Power Systems, Vol.1, n.2, pp.303-310, Feb. 2006.

[25] Rahman, K., Patel, N., Ward, T., Nagashima, J., Caricchi, F., Crescimbini, F., Application of direct drive wheel motor for fuel cell electric and hybrid electric vehicle propulsion system, $39^{\text {th }}$ IEEE Ind. Applications Conf., Seattle, USA, 3-7 Oct. 2004.

[26] Andriollo, M., Bettanini, G., Martinelli, G., Morini, A., Tortella, A., Efficiency Comparison of In-wheel PM Motors for Bus Propulsion, $17^{\text {th }}$ Int. Conf. on Electrical Machines (ICEM2006), Chania, Greece, 2-5 Sept. 2006.

[27] Wei W., Zongryu L., Rongrong X., INS/GPS/Pseudolite Integrated Navigation for land Vehicle in Urban Canyon Environments, Proc. of the 2004 IEEE Conf. on Cybernetics and Intelligence Systems, Singapore, 1-3 Dec. 2004, pp. 1183-1186.

[28] Farrel J. A., Tan H. S, Yuang Y., Carrier Phase GPS-Aided INS-Based Vehicle Lateral Control, Journal of Dynamics Systems, Measurement and Control, Trans. of the ASME, Vol. 125, pp. 339-353, Sept. 2003.

[29] Tan H. S., Bougler B, Farrel J. A., Yang Y., Automatic Vehicle Steering Controls: DGPS/INS and Magnetic markers, Proc. of the 2003 American Control Conf., Denver, USA, 4-6 June 2003.

[30] Yih P., Ryu J, Gerdes J. C., Modification of Vehicle Handling Characteristics via Steer-by-Wire, Proc. of the 2003 American Control Conf., Denver, USA, 4-6 June 2003, pp. 60-65.

[31] Roth S., Singh S., Application of robust, high accuracy positioning for autonomous ground vehicles, Proc. of AUSVI Unmanned Systems North America 2004, Aug. 2004.

[32] Huang J., Tan H. S., A Low-Order DGPS-Based Vehicle Positioning System Under Urban Environment, IEEE/ASME Trans. on Mechatronics, Vol. 11, n. 5, pp. 567-575, Oct. 2006.

[33] Tan H. S., Huang J., DGPS/INS-based Vehicle Positioning with Novel DGPS Noise Processing, Proc. of the 2006 American Control Conf., Minnesota, USA, 14-16 June 2006, pp. 3966-3971. 
[34] Ryu J., Gerdes J. C., Integrating Inertial Sensors with GPS for Vehicle Dynamics Control, Journal of Dynamics Systems, Measurement and Control, Volume 126, Issue 2, pp. 234-254, June 2004.

[35] Ryu J., Gerdes J. C., Estimation of Vehicle Roll and Road Bank Angle, Proceedings of the 2004 American Control Conf., Boston, MA, 30 June-2 July 2004, vol. 3, pp. 2110-2115.

[36] Ryu J., Rossetter E. J., Gerdes J. C., Vehicle Sideslip and Roll Parameter Estimation using GPS, AVEC $20026^{\text {th }}$ Int. Symp. on Advanced Vehicle Control, Hiroshima, Japan, 2002.

[37] Redmill K. A., Kitajima T., Özgüner Ü., DGPS/INS Integrated Positioning for Control of Automated Vehicle, 2001 IEEE Intelligent Transp. System Conf. Proc., Oakland, USA, 25-29 Aug. 2001, pp. 172178.

[38] Caporali A., Basic Direction Sensing with GPS, GPS World, March 2001, pp. 44-50.

[39] Caporali A., Dalla Torre A., Praticelli N., Interferometric Attitude and Direction Sensor Using GPS Carrier Phase Data, Reports on Geodesy, n. 2 (65), 2003, pp. 221-233.

[40] Di Corato R., Falzini S., Beccarini A., Caporali A., Morini C., Pepi T., SISE prediction and Iono/Tropo Corrections in a Local augmentation System, Proc. of Institute Of Navigation (ION) Tech. Meeting, San Diego, USA, 22-24 Jan. 2007, pp 979-989. 